\title{
periferio
}

\section{DIÁLOGOS TÔNICOS COM CRIANÇAS SURDAS A PARTIR DE PRÁTICAS PSICOMOTORAS}

\author{
Katia Bizzo Schaefer ${ }^{1}$ \\ Colégio Pedro II
}

\section{Resumo}

O presente artigo tem a pretensão de convidar o leitor a refletir sobre os diálogos tônicos que ocorrem com crianças surdas no contexto da Educação Infantil, especificamente no Instituto Nacional de Educação de Surdos, localizado no Rio de Janeiro. Pelo olhar da Psicomotricidade, dos estudos sobre surdez e da filosofia nietzschiana que aborda o corpo como vontade de potência, são apresentados recortes de uma pesquisa de campo com crianças que possibilitam ampliar as reflexões e repensar as práticas e os diálogos estabelecidos com crianças surdas através de seus corpos: o que se evidencia, o que se aprisiona e o que se potencializa? Como olhar para as crianças surdas em suas potencialidades a partir dos diálogos tônicos estabelecidos? Como empoderá-las diante de uma sociedade que não reconhece o valor dos sujeitos surdos? A Psicomotricidade traz possibilidades de desenvolver outras formas potentes não só de comunicação, mas também de atuação e apreensão do mundo em que vivem. Através de uma educação psicomotora, é possível perceber o corpo como fio condutor de todo esse processo e as crianças são convidadas a perceberem seus corpos pela saúde e pela sua força. A deficiência é afirmada, mas se torna algo menor diante de tantas possibilidades vitais, potentes e relacionais.

Palavras-chave: diálogos tônicos; crianças; surdez; psicomotricidade; filosofia nietzschiana

\footnotetext{
${ }^{1}$ Doutora em Educação (UERJ, 2015), professora de Educação Infantil do Colégio Pedro II, atualmente na função de Coordenadora Adjunta Pedagógica do Centro de Referência em Educação Infantil Realengo do Colégio Pedro II - Rio de Janeiro/RJ. katia.b.schaefer@gmail.com
} 


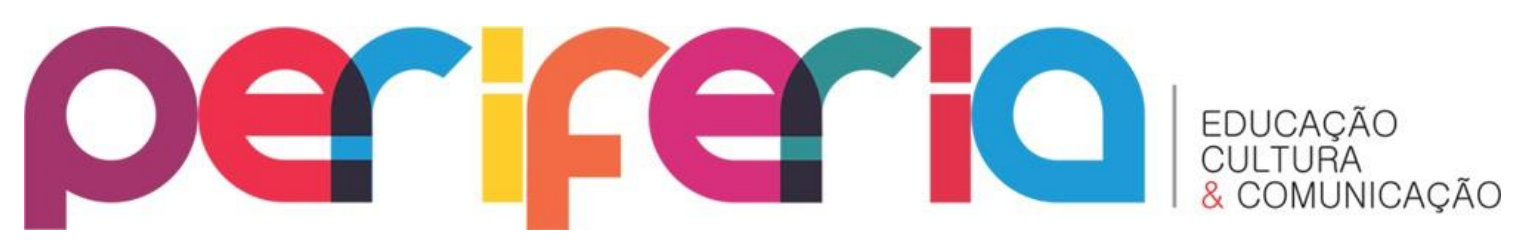

TONIC DIALOGUES WITH DEAF CHILDREN FROM PSYCHOMOTOR PRACTICES

\begin{abstract}
This article intends to invite the reader to reflect on the tonic dialogues that occur with deaf children in the levels of Preschool, specifically at the National Institute of Deaf Education, located in Rio de Janeiro. From the perspective of Psychomotricity, the studies on deafness and the nietzschean philosophy that perceive the body as will to power, this article presents clippings from a field research with children that make it possible to broaden the reflections and rethink the established practices and dialogues with deaf children through their bodies: what is evident, what is imprisoned and what is potentialized? How to look at deaf children in their bodies as will to power from established tonic dialogues? How can we empower them in the face of a society that does not recognize the value of deaf individuals? Psychomotricity brings possibilities to develop other powerful forms not only of communication, but also of acting and apprehension of the world in which they live. Through a psychomotor education, it is possible to perceive the body as the guiding thread of this whole process and the children are invited to perceive their bodies for health and their strength. The deficiency is affirmed, but it becomes lesser in the face of so many vital, powerful and relational possibilities.
\end{abstract}

Keywords: tonic dialogues; children; deafness; psychomotricity; nietzschean philosophy 


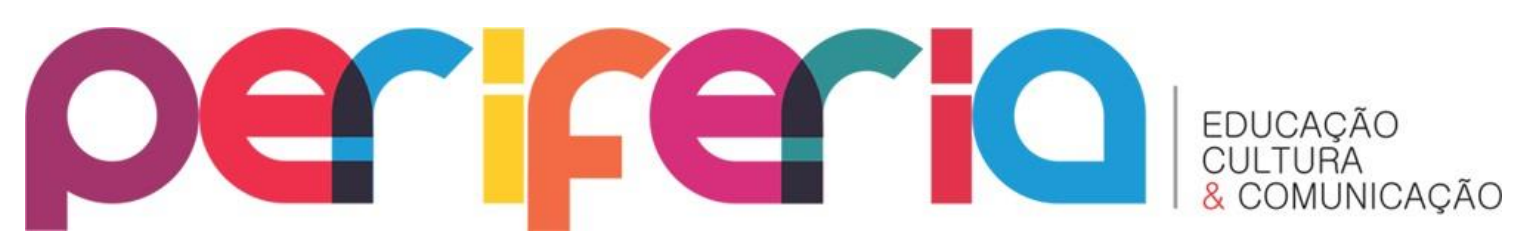

\section{QUESTÕES INICIAIS}

Em estudos sobre Psicomotricidade, pensar o corpo do sujeito, seja este ouvinte ou surdo, não está desconectado de sua linguagem, afetos, relações e aprendizagens. Em muitos casos, há o desejo de que o grupo trabalhado com práticas psicomotoras consiga inibir sua comunicação verbal para deixar fruir de forma mais intensa os seus sentidos e afetos. Nem sempre essa tarefa é fácil de ser cumprida, pois calar o verbo convida a um olhar para si que pode trazer angústias, incertezas e medo.

Desde muito pequenos, nós, ouvintes, aprendemos a nos comunicar com a linguagem verbal e, nesse processo, também nos afastamos de linguagens não tão racionais, que privilegiam as expressões, os movimentos, a respiração, as contrações e expansões corporais, os sentidos, a troca de olhares e tantas outras formas de nos comunicarmos conosco mesmos, com os outros e até com o espaço que ocupamos.

Buscar essa reconexão parte, inicialmente, de um desejo e uma abertura para essa proposta que seja forte suficientemente para enfrentar os incômodos que uma redescoberta ou descoberta de si pode provocar. Quanto mais nos apropriamos da linguagem verbal, mais podemos nos distanciar dessa tarefa e, consequentemente, mais difícil pode se tornar o processo de reencontro conosco mesmos.

A contribuição de Morin (2004) sugere pensar o ser humano como um ser complexo, que só pode ser compreendido em suas relações com o outro, consigo mesmo e com o ambiente e, mesmo assim, haverá sempre o duplo sentido, as múltiplas interpretações, a incerteza, o bem e o mal convivendo juntos, o certo e o errado, o pensamento, os movimentos e a alma... tudo presente em um único corpo que se relaciona com outros, tendo o que é da ordem da objetividade compreendendo a subjetividade humana e vice-versa.

Diante desse olhar para o pensamento complexo de Morin, cabe trazer, no campo da Psicomotricidade, Lapierre e Aucouturier, na obra A simbologia do movimento (2004), na qual os autores chamam a atenção para a 


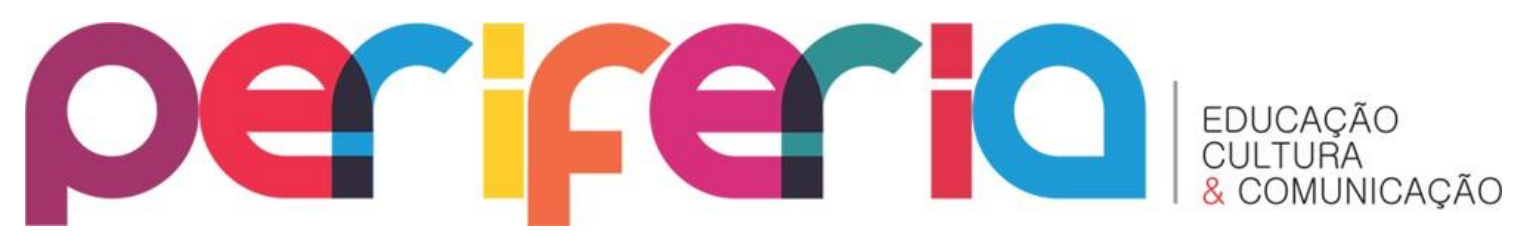

comunicação corporal, enfatizando que quando ela é observada e estimulada, pode levar o aluno a atingir camadas profundas de seu próprio ser, ampliando suas possibilidades de autoconhecimento e, em consequência, alterando o seu "porvir a ser" (p. 12). Em contrapartida, os autores levantam as questões observadas em suas pesquisas de campo, ao perceberem que o olhar para 0 interior, ou seja, a proximidade com um pensamento inconsciente, assusta os educadores, já que estes, sem poder controlar o pensamento e o conhecimento porvir desses, e na impossibilidade de compreender as consequências dessas novas composições, consideram tal aproximação como patologias mentais, nas quais nada de bom pode surgir daí: “É, em suma, o que há de 'ruim' na criança, o que faz com que ela não reaja de 'forma racional' à ação educativa. Apenas o 'desajustado' tem o privilégio - do qual às vezes abusa - de nos preocuparmos com o seu inconsciente." (LAPIERRE; AUCOUTURIER, 2004, p. 13).

Desta forma, ignoramos as pulsões do corpo no decorrer da vida, principalmente quando as palavras ganham forma e um sucessivo requinte. Ainda há de se instaurar uma prática que valorize a relação existente e rica entre ação e pensamento. O corpo em movimento é contido na escola (LAPIERRE; AUCOUTURIER, 2004, p. 39), mas ele continua pulsando, buscando espaço para sua vivacidade, buscando uma vivência emocional que "é encontrada, inicialmente, no estado mais puro, no nível das situações espontâneas que são determinadas, todas elas, pela busca do prazer de vivenciar o seu corpo na relação com o mundo, com o espaço, com os objetos, com os outros." (LAPIERRE; AUCOUTURIER, 2004, p. 32). Será que podemos oferecer esse espaço?

No caso das crianças surdas, especificamente, qual o espaço que possibilitamos para que elas se comuniquem, se expressem, vivenciem a potencialidade de seus corpos, durante o período de aprendizagem escolar? Como seria estabelecer práticas psicomotoras com as crianças surdas, diante dessas reflexões, entendendo que as crianças ainda estão no processo de 


\section{periferio}

apropriação da linguagem verbal e que esse processo ainda pode acontecer de forma bem precária?

Diante destas reflexões, mostra-se relevante abrir um campo de pesquisa que pode ampliar as possibilidades de aprendizagem e de atuação de alunos surdos não só dentro das instituições escolares, mas, também, além desses muros, na relação com uma sociedade em que a diversidade predomina e na qual se espera e se deseja uma relação de respeito e valorização das diferenças, de tal maneira que estas não sejam tratadas de forma menor.

Quem melhor pode defender as necessidades da comunidade surda na sociedade brasileira são os próprios surdos e, para isso, eles precisam estar dotados e conscientes de suas potencialidades. Para tanto, buscamos vivenciar experiências corporais que possibilitassem que eles entrassem em contato com o próprio corpo, percebendo que a surdez não é impeditiva do desenvolvimento e atuação plena desses sujeitos na sociedade em que vivem.

Foi com esse intuito que criamos um grupo no Programa de Iniciação Científica do Instituo Nacional de Educação de Surdos (INES), do Departamento de Ensino Superior (DESU), com o projeto "Estudos de bases filosóficas sobre a importância do trabalho de corporeidade na educação de surdos", que aconteceu no período de abril de 2012 a agosto de 2013. A proposta era desenvolver esse estudo na Faculdade de Pedagogia Bilíngue do INES, buscando parceria para pesquisa de campo com o Colégio Aplicação da própria instituição. 0 objeto de estudo, então, era a prática pedagógica realizada com alunos surdos, na Educação Infantil, em função de um olhar voltado para as potências corporais dos mesmos, partindo do princípio do quanto é importante que as crianças desenvolvam a linguagem corporal como ferramenta de comunicação com a sociedade e com elas mesmas. Que resultados poderiam existir nas vidas dos alunos surdos, se o corpo também pudesse dialogar e se expressar de forma mais efetiva nos grupos escolares, mesmo sem o domínio da linguagem verbal, sendo esta oralizada, escrita ou através de língua de sinais? 


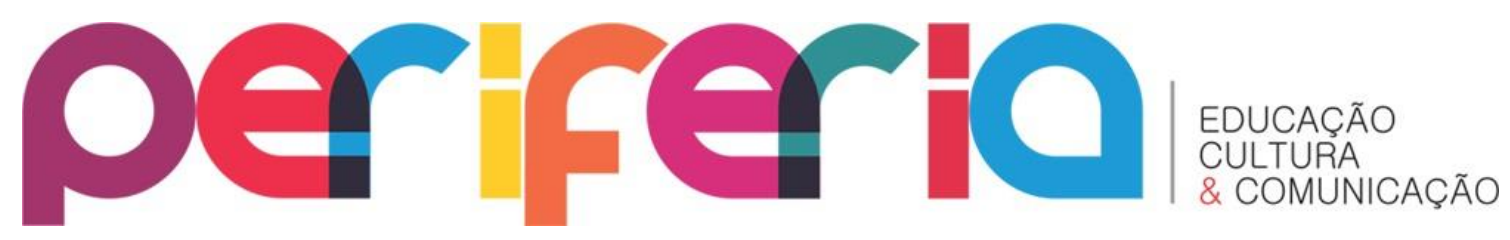

A partir destas questões, encontramos na Filosofia importantes referencias teóricos, como os estudos de Nietzsche sobre as potencialidades do corpo de cada sujeito, entendendo o corpo como fio condutor do desenvolvimento humano e como vontade de potência diante da vida. Para essa base filosófica, recorremos às obras Ecce homo: de como a gente se torna o que a gente é (2008), O nascimento da tragédia (2007) e Assim falou Zaratustra: um livro para todos e para ninguém (2011). A pesquisa também se baseou nos estudos sobre Psicomotricidade, a partir das teorias de Lapierre e Aucouturrier (2004) e nos estudos sobre surdez, a partir de Skliar (2010), que nos convida a repensar o lugar dos surdos na sociedade através do olhar para as diferenças e da valorização destas, e Lulkin (2010), que situa a história da docilização dos corpos de sujeitos surdos na sociedade e nas instituições educacionais.

\section{O CAMPO DE PESQUISA}

O grupo de pesquisa, inicialmente, se reunia para estudar sobre concepções de infância, práticas de pesquisa com crianças, estudos sobre surdez e Psicomotricidade e reflexões filosóficas. Tais discussões, leituras e debates nos ajudaram a montar um plano de ação em conjunto com o Setor de Educação Infantil no INES (SEDIN), com o apoio da coordenação pedagógica do mesmo e a autorização prévia dos pais dos alunos com os quais estaríamos em contato.

Foi uma pesquisa-ação (DELGADO; MÜLLER, 2005) que objetivou atender a todas as crianças/alunos da Educação Infantil, no turno da tarde, semanalmente, respeitando o horário pré-estabelecido pela coordenação do setor, de forma a contribuir com a prática pedagógica do mesmo e buscar parcerias nesta pesquisa. Desta forma, uma vez por semana, nos reuníamos com duas turmas no mesmo dia (totalidade do turno), com propostas diferenciadas de práticas pedagógicas, tendo o corpo como fio condutor do trabalho, passando pelas questões de corporeidade e afeto atreladas às 


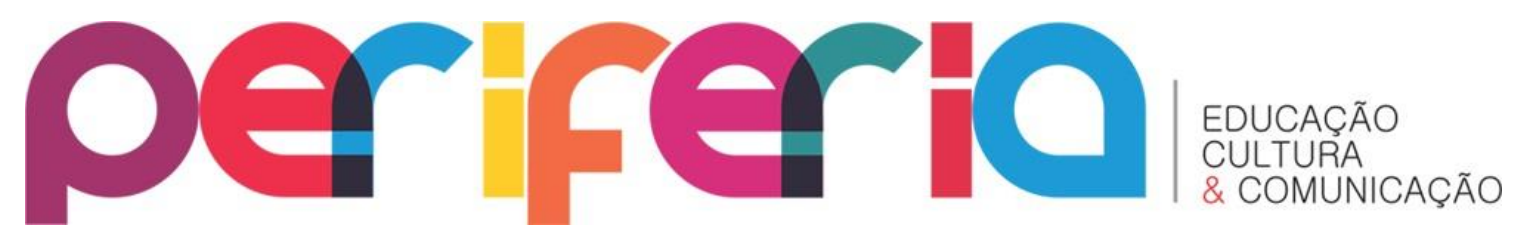

diferentes linguagens e expressões das crianças. Os encontros eram filmados e fotografados e esse material tornou-se fonte de estudos sobre a pesquisa em questão.

Em cada encontro, realizávamos propostas com cordas, bambolês, caixas de papelão, tecidos e outros materiais, sendo escolhidos um ou mais por encontro, para mediarmos a relação dos alunos entre eles, deles conosco e deles com os objetos e o espaço. Esses materiais eram previamente pensados, a partir do estudo da Psicomotricidade Relacional (AUCOUTURIER; LAPIERRE, 2004), que nos ajudava a entender diálogos possíveis entre os corpos e os objetos, a partir dos convites simbólicos que estes elementos provocavam nesta relação. Como exemplo, podemos citar as bolas, que utilizamos no primeiro encontro, devido ao convite para um sujeito se relacionar com o outro, como jogar a bola para que o outro a receba, seja criança ou adulto. Esse material também é favorável por já ser de conhecimento das crianças, minimizando o estranhamento em relação aos adultos que se apresentam pela primeira vez ao grupo escolar e com uma proposta também diferente das vivenciadas no cotidiano da Educação Infantil.

Ainda na vivência, contamos sempre com três regras básicas, que foram repetidas e reforçadas em todos os encontros. Foram elas: cuidado com o próprio corpo, cuidado com o corpo do outro e cuidado com o ambiente. Essas regras são fundamentais dentro da perspectiva da Psicomotricidade, na qual buscamos a percepção do corpo diante destas três dimensões (o próprio corpo; a relação do seu corpo com o corpo do outro; e a relação do seu corpo e do corpo do outro com o espaço que ocupam). Outros combinados puderam ser formulados e reformulados no decorrer das dinâmicas, como tirar os sapatos no início dos encontros e calçá-los no final; não sair do espaço em que nos encontrávamos etc.

Com o grupo composto por, no mínimo, três pessoas, uma sempre ficava responsável pela filmagem e fotografia da vivência, para que pudéssemos, em outro momento, rever a dinâmica e discutir, refletir e registrar sobre o nosso objeto de pesquisa. 


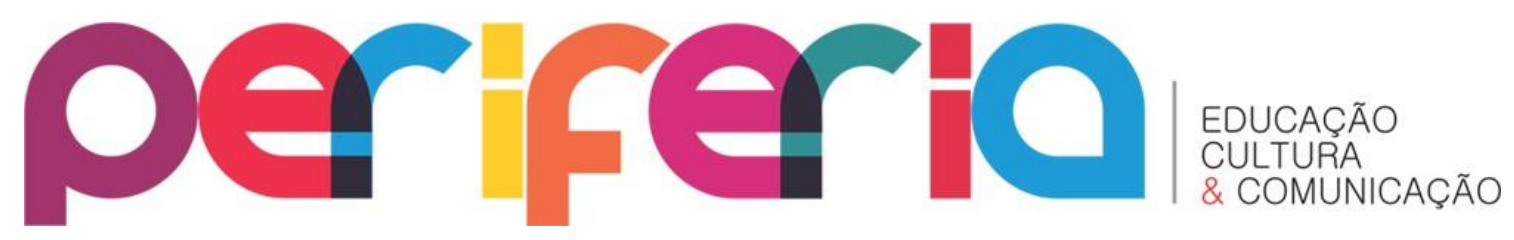

O encontro com cada grupo de crianças durava entre cinquenta minutos e uma hora, incluindo organização do espaço, experiências com o corpo e fechamento do encontro. O espaço utilizado foi combinado com a coordenação do setor em questão, de forma a não prejudicar o andamento do trabalho pedagógico da instituição. Da mesma forma, os dias da semana, a formação de cada grupo, encontros e horários estabelecidos também foram combinados com a coordenação pedagógica.

Após cada encontro, dividíamos as nossas impressões, elaborávamos reflexões em diálogo com o material teórico de base e pensávamos em intenções e estratégias para a próxima semana. Foi assim que resolvemos repetir a bola e acrescentar mais um material no segundo encontro. Entendemos que a bola ajudaria a fortalecer os nossos vínculos, a partir de uma memória afetiva já construída no primeiro dia. Acrescentamos os tecidos, por estes convidarem a uma relação maleável, aderente, protetora e intensa. O que surgiria no encontro dos corpos das crianças surdas com adultos ouvintes e com esses materiais? Tal questão sempre antecedia as vivências, pois o planejamento não determinava o caminho a ser seguido. Era um ponto de partida para acontecimentos que se constituíam a cada instante, nas relações que eram vivenciadas. Enfrentávamos as incertezas e nos abríamos para constantes descobertas, afetos e transformações.

Desde o primeiro encontro, observamos as crianças, as relações que estabeleciam com o grupo, conosco, com elas mesmas e com o espaço. Poucas sabiam algo sobre Língua de Sinais Brasileira (LIBRAS), o que tornava o diálogo tônico mais potente entre nós. Os olhares, o corpo contraído ou relaxado, as expressões com a boca, a velocidade dos movimentos, o toque no corpo do outro, o equilíbrio, a respiração... tudo se tornava mais evidente para nos conhecermos melhor e nos comunicarmos.

Na primeira turma, tínhamos uma criança que, além de surda, havia sido diagnosticada como portadora do Transtorno do Espectro Autista (TEA). 0 


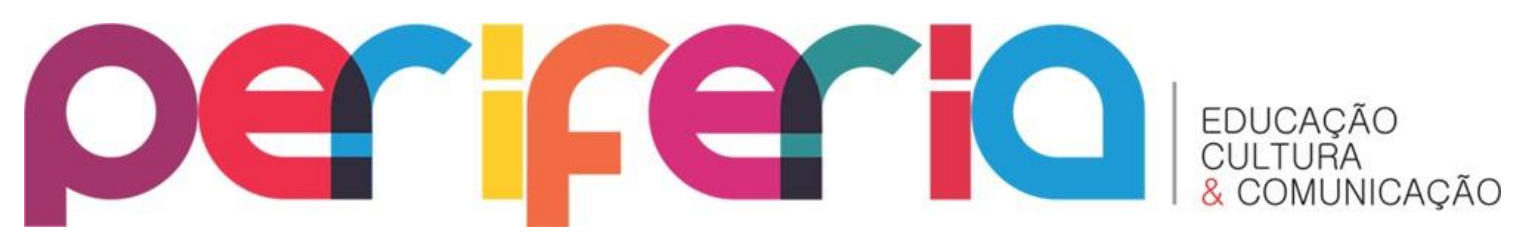

Marcelo ${ }^{2}$ era carinhoso, gostava de ficar no nosso colo, observava todas as crianças e adultos e adorava bolas. Sempre que as colocávamos no saco para guardá-las, ele tentava nos impedir, demonstrando que não queria que aquela proposta findasse. Manter as bolas no segundo encontro também foi uma forma de acolhermos o seu desejo. Marcio enxergava pouco e também era bem carinhoso. Nos observava atentamente e nos imitava, sempre com um sorriso tímido em seus lábios. Ele era muito doce e não reagia quando os amigos o empurravam ou até mesmo batiam nele. Nós o protegíamos, mas também nos incomodávamos com sua passividade. Um dia, a avó de Marcio nos questionou sobre a mudança do seu comportamento no decorrer dos encontros, verbalizando que ele estava mais desobediente em casa, questionando mais as decisões dos adultos. Ela associou que isso poderia estar acontecendo como consequência do trabalho que estávamos realizando com ele e sua turma e queria nos ouvir em relação a isso. Conversamos com ela sobre a importância dele se impor diante da vida, mostrando seus contentamentos, mas também seus descontentamentos e que estávamos felizes com esse retorno. Conhecemos Marcio muito passivo diante dos acontecimentos e, posteriormente, já não permitia que batessem nele, criava brincadeiras e ousava mais em seus movimentos. Mostrava-se mais afirmativo e seguro na relação com os colegas e a alegria e confiança em si mesmo eram evidentes. Após conversarmos, sua avó mostrou-se mais tranquila e confiante em relação à mudança de postura do neto.

João era muito agitado e agressivo. Mordia as outras crianças, batia, empurrava e se recusava a cumprir os combinados com a turma. Era muito intenso nos seus movimentos e pouco nos olhava, evitando um diálogo que pudesse recriminar suas atitudes. Aos poucos, João passou a estabelecer um diálogo tônico mais leve e tranquilo, no qual nossos olhares se cruzavam com alegria, entendimento e cumplicidade. Conseguíamos conversar, combinar e nos respeitar, mas para chegar nesse nível relacional, os conflitos foram

\footnotetext{
${ }^{2}$ Ao longo do texto, utilizamos nomes fictícios ao nos referirmos às crianças da pesquisa, com o intuito de preservar a identidade das mesmas.
} 


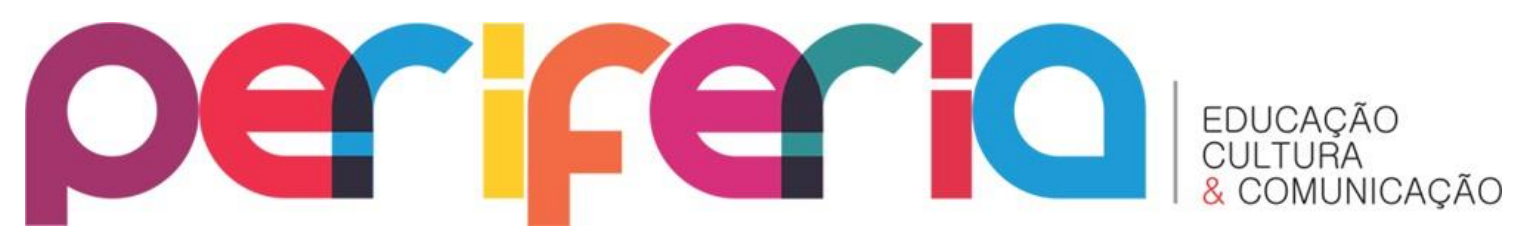

necessários. João nos mordeu, puxou nossos cabelos, agrediu seus colegas, não cuidava do espaço e não permitia uma comunicação olho no olho. Precisamos, algumas vezes, por medida de segurança e para dar contorno à situação que se apresentava, conter seu corpo, mostrar nosso descontentamento com suas atitudes e criar uma relação de respeito mútuo entre nossos corpos, na qual evidenciávamos o que nos incomodava e o que nos deixava felizes quando estávamos juntos. Não era uma relação de culpabilização ou moralização, mas de busca de um entendimento e de um respeito mútuo. Para tanto, buscávamos seu olhar para estabelecer uma comunicação além de palavras e mostrávamos algumas possibilidades de atuação que ele poderia experimentar nesses encontros, de forma lúdica, afetiva e respeitosa de todas as partes.

A segunda turma era composta por crianças de 5 a 6 anos. Eles buscavam mais o contato verbal, em relação à primeira turma, porém o diálogo tônico era mais evidente e eficiente na comunicação do que o diálogo verbal. Renata era uma criança muito alegre e que gostava de cuidar de seu grupo e dos adultos. Sempre muito atenta, buscava mais o contato com as pessoas do que com os objetos. Neimar se concentrava mais na relação com os objetos. Gostava de criar diferentes contextos com o material que propúnhamos. Torres com caixas ou blocos de espuma, armadilhas com cordas ou elástico, inventar brincadeiras com as bolas... fazia tudo de forma muito organizada e cuidadosa e ficava chateado quando algum colega pegava um dos materiais que ele estava utilizando ou quando destruíam sua criação pelo prazer de brincar de destruir o que se construía. Para dar conta de suas produções, buscava todos os materiais possíveis, o que inviabilizava o uso dos mesmos pelos colegas. Essa situação normalmente gerava conflitos entre eles, que observávamos atentamente, mas só intervíamos no sentido de propor outra brincadeira. Não julgávamos ou interrompíamos a situação, até para deixá-los resolverem seus conflitos.

Dentro de um ambiente escolar, essa proposta parecia absurda, pois há o costume de impedirmos os conflitos e brigarmos com as crianças que os 


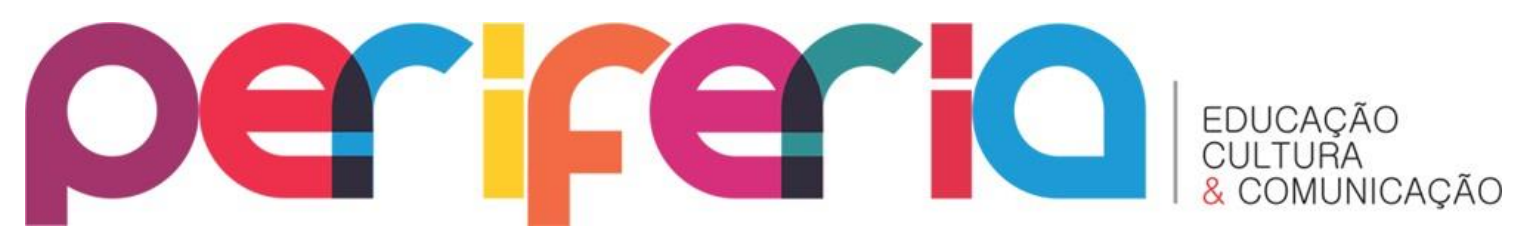

criam, mas não era assim que direcionávamos as nossas ações. Estávamos lá para dialogar com eles e convidá-los a perceber a potência de seus corpos, intensificando-as na busca de um reencontro com eles próprios, com os outros e com o ambiente. Não era a nossa intenção estabelecer práticas moralizantes ou censurá-los.

Nessa mesma turma, Carlos e Daniel testavam seus limites e os nossos também. Gostavam de transgredir as poucas regras que estabelecíamos: cuidar do seu corpo, do corpo do outro e do ambiente. Eram apenas três regras. 0 restante era possível, mas eles queriam entender o que fazíamos ali. Por que podiam tantas coisas? Por que não podiam outras? Então nos testavam todas as vezes. Batiam nos colegas e provocavam situações de descontentamento com o restante do grupo, como atrapalhar as brincadeiras criadas, por exemplo. Estávamos sempre por perto, entendendo a necessidade e o desejo deles viverem essas situações e acolhendo seus impulsos. Quando preciso, colocávamos os limites necessários em relação aos nossos próprios corpos, mas também entendíamos o quanto essas transgressões serviam de oportunidades para trabalhar as questões de todo o grupo. Como lidavam com suas frustrações, agressividade e raiva? Como cada um conseguia impor os limites do seu próprio corpo ao outro?

Poderíamos citar diferentes questões desafiadoras na relação com cada criança que surgiam em nossas relações, observações, diálogos e reflexões, mas recortamos estas por considerá-las as mais evidentes em nossas discussões.

As professoras das turmas assistiram algumas vivências e mostraram-se felizes por estarmos lá, em parceria com o trabalho delas. Por outro lado, percebíamos o quanto parecia difícil para elas entender a nossa atuação. Líamos em seus olhos: "como deixam as crianças agirem de forma tão impulsiva?". Sentimos o tom de cuidado e preocupação das professoras conosco. Uma delas chegou a perguntar se preferíamos retirar uma criança dos encontros, para que ela não atrapalhasse o grupo. Respondemos que aquela criança era uma das que mais precisava estar ali, por ela e por nós. Ao 


\section{periferio}

assistir um dos vídeos, percebemos uma professora pedindo para uma criança não subir em nossas costas para não nos cansar. Era um momento em que vários subiam e faziam de nós cavalos para que cavalgassem. Não vimos, na hora, essa intervenção, e entendemos que ela agiu com a intenção de cuidar de nós, mas éramos nós que teríamos que dar esse limite, se fosse o caso. Não era! Aceitamos a brincadeira e, apenas alguns minutos depois, nós mesmas sinalizamos que estávamos cansadas para que procurassem outras possibilidades de brincar. Essas intervenções são comuns na prática escolar, mas não pelo olhar da Psicomotricidade e da potencialização dos corpos. Por sua vez, também precisávamos acolher os limites de atuação destas profissionais, já que nos propomos a fazer uma pesquisa no cotidiano da Educação Infantil.

Para essas propostas, adaptávamos um espaço do SEDIN e a professora poderia estar ou não presente. A questão dos espaços foi um desafio já esperado, pois entendemos o quanto saía da rotina propor momentos de atividades corporais, com movimentos amplos. Estes espaços precisavam ser fechados, amplos, seguros e, de preferência, vazios de objetos e móveis, para podermos apenas oferecer os materiais que levávamos.

Apesar do SEDIN ter uma sala de Psicomotricidade, a mesma não estava em condições de uso. Por isso, inicialmente tentamos adaptar uma sala de aula, o que logo provocou preocupação com a integridade dos murais e trabalhos da professora do local e, em seguida, a sala não foi mais disponibilizada pela coordenação. Então, optamos pelo pátio coberto, mas não tínhamos como tirar os brinquedos do mesmo. Essa condição foi um desafio permanente em todas as vivências apresentadas, o que nos levou a considerar os brinquedos do pátio como parte das vivências, além dos materiais que oferecíamos.

Sempre contamos com a equipe completa - três pesquisadores - de forma que podíamos alternar quem agia no contato direto com as crianças, quem fotografava ou filmava as vivências. Por vezes, pudemos contar com mais alguns participantes, que também fizeram parte dos estudos e 


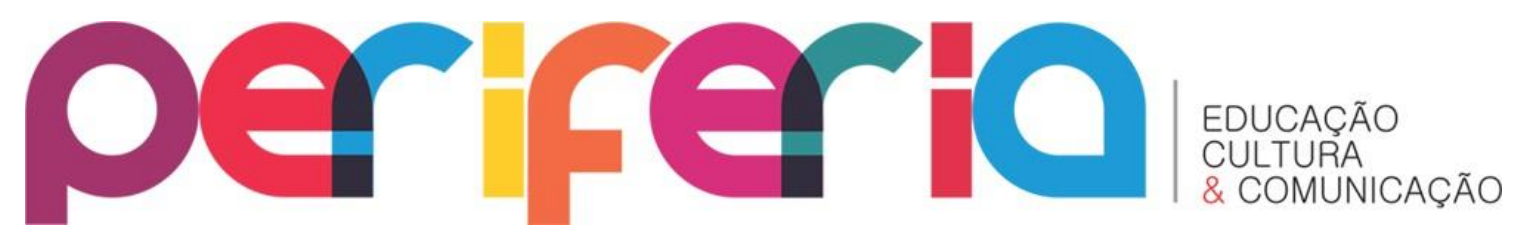

acompanharam o projeto da pesquisa, como ação voluntária. Entre o período pesquisado, contamos com semanas que não íamos ao SEDIN, em função de feriados ou outros eventos. Assim, totalizamos dez vivências com eles, de março a julho de 2013, todas registradas (filmes e fotos), revistas e discutidas pelo grupo. 0 contato com as professoras de turma também era constante e proveitoso, atendendo a uma riqueza de interações e parceria na proposta.

Houve contato com alguns familiares, pois os encontrávamos informalmente, em momentos diferentes pelo espaço do INES, e, como as crianças costumavam vir em nossa direção para nos abraçar, aproveitamos para dialogar com eles sobre a pesquisa e, assim, também colher informações importantes, como relatos de mudança de comportamento das crianças fora da escola, por exemplo. Cabe ressaltar que, antes de iniciarmos a pesquisa de campo, a coordenação do SEDIN organizou uma reunião nossa com todos os responsáveis para explicarmos nossa proposta e pedirmos a autorização deles para que as crianças participassem. Todos concordaram e assinaram a autorização.

No decorrer dos dez encontros, levamos cordas, caixas de papelão e tinta; fizemos teias de elástico, brincamos de bola de sabão, utilizamos blocos de espuma que se encontravam na sala de Psicomotricidade do SEDIN, fizemos experiências gustativas com frutas, legumes e verduras, enfim... utilizamos materiais diversos que possibilitaram diferentes interações entre o material e as crianças, sempre acompanhados de um estudo e um planejamento nosso para cada encontro.

No momento de finalizar os encontros, havia uma tensão costumeira. Em ambas as turmas, as crianças não queriam ir embora. Era a hora de guardar o material, colocar os sapatos e lavar as mãos para irem para o lanche. Esse momento se tornava intenso e desafiador para todos nós. Não queríamos terminar nossas vivências com tristeza e choro. Isso nos incomodava bastante. Buscamos alternativas diversas para finalizar as propostas. No final, já aceitavam com mais tranquilidade, mas uma de nós ia com eles até o lanche, para garantir a qualidade positiva dessa transição. 


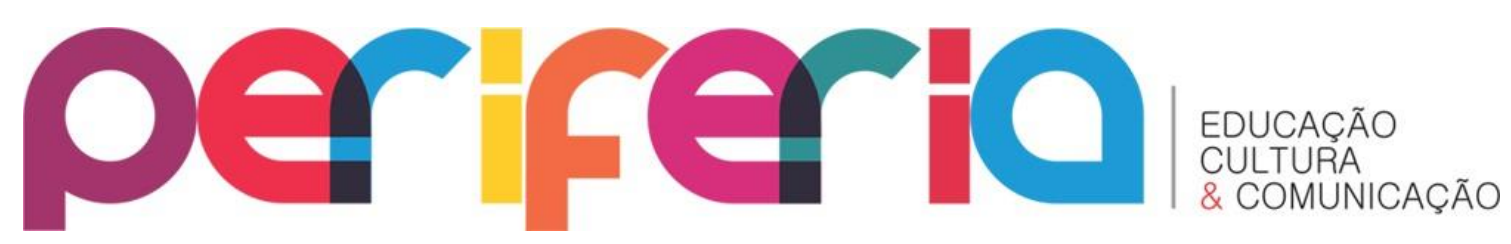

Entre o momento de uma turma e de outra, parávamos para lanchar e nos recompor. 0 nosso corpo era material sempre presente nesses encontros e bastante disponível para as crianças, por isso a necessidade de uma pausa, para respirarmos, nos olharmos e nos restabelecermos para um novo grupo.

Não era apenas as crianças que se potencializavam com essas propostas. Cada vivência nos enriquecia de possibilidades de reflexões, aprendizagens e planos de atuação e relação com elas. Fomos transformadas por essa pesquisa e pelas crianças que tanto se entregavam a esses momentos. Havia alegria, emoção, afeto, transformação. No decorrer das vivências, intensificamos nossos estudos em Nietzsche para buscarmos respostas e mais perguntas em relação ao corpo, como vontade de potência e fio condutor para a aprendizagem e desenvolvimento humano.

\section{A FILOSOFIA DE NIETZSCHE NA RELAÇÃO ENTRE CORPOS DE ADULTOS E CRIANÇAS}

Foi em Nietzsche que encontramos muitas das respostas que procurávamos. Na obra Nascimento da Tragédia (2007), Nietzsche descreveu o que ele definiu como instintos apolíneo e dionisíaco. 0 instinto apolíneo remeteria ao Deus grego Apolo, Deus da beleza, da aceitação pelo outro; Deus admirado por atender os parâmetros de aceitação e beleza determinados pelo olhar do outro. 0 instinto apolíneo buscava admiração e, para tal, seguia padrões sociais que levariam o sujeito a esse reconhecimento. Precisamos desse instinto para vivermos bem em sociedade, mas também há outro instinto, que Nietzsche definiu como dionisíaco. Também baseado na mitologia grega, Dionísio era o Deus da embriaguez; desmedido, espontâneo, que não se preocupava com o que os outros iriam pensar dele, apenas fazia o que desejava, se entregando aos prazeres da vida sem culpa, sem medo, sem ressentimento; vivia intensamente o aqui e agora sem preocupação com as consequências. Diante desses dois instintos, seria preciso encontrar o equilíbrio entre eles e a busca desse equilíbrio poderia ocorrer por toda a 


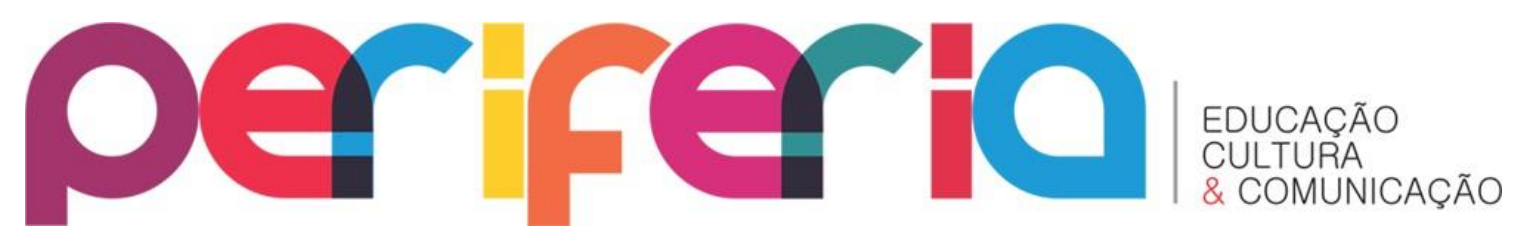

vida. Como permitir nossos prazeres e sermos aceitos na moralidade do outro? Como não abrir mão nem de uma condição nem de outra? Essa seria uma das grandes questões vitais que enfrentamos, na concepção desse filósofo. A reflexão sobre esses instintos nos instigou a pensar nas expressões, nos desejos e na relação que estabelecemos, enquanto adultos e educadores, com as crianças. No desejo de serem aceitas, será que permitiriam liberar seus desejos pulsantes? Até que ponto estaríamos abertas a permiti-los, caso surgissem? 0 que buscávamos nessas relações?

$\mathrm{Na}$ sua obra Assim falou Zaratustra: um livro para todos e para ninguém, Nietzsche (2011) trouxe a passagem Das três metamorfoses, na qual descreve as transformações do espírito humano para que ele possa chegar a ser o que se é. A primeira seria quando o espírito se torna camelo, que deve carregar o peso da vida, da culpa, da responsabilidade, dos compromissos. Em seguida há a transformação no espírito de leão, raivoso, guerreiro, selvagem, que diz não ao peso que o camelo carrega. 0 leão percebe que não deve nada e não quer mais esse peso! Usa de sua agressividade para romper esse paradigma e afirmar o que quer e o que não quer. E de leão transforma-se em criança - a última das metamorfoses para chegar a ser o que se é. Espírito livre, leve, que questiona, cria, inventa e reinventa o que vive e como vive. Espírito brincante, bailante, que dá lugar ao prazer e à beleza. Espírito que se afirma (eu sou!) sem medo, sem culpa, apenas sendo o que é em toda sua potência.

Pensar nessas metamorfoses nos leva a questionar o porquê dessa última transformação ser exatamente a criança. Vivemos em uma sociedade que não valoriza esse estado de vida, que questiona o que as crianças querem ser quando crescerem, como se já não fossem muito por serem crianças. Em uma sociedade onde a produção capitalista fala mais alto, o sujeito ganha valor quando pode produzir, ter profissão, ter renda. Nesse sentido, a criança representa despesa ou investimento para um futuro no qual ela possa "ser alguém". Nietzsche provoca a repensar essas perspectivas quando valoriza o estado de ser criança, para além de um tempo cronológico, levando a um 


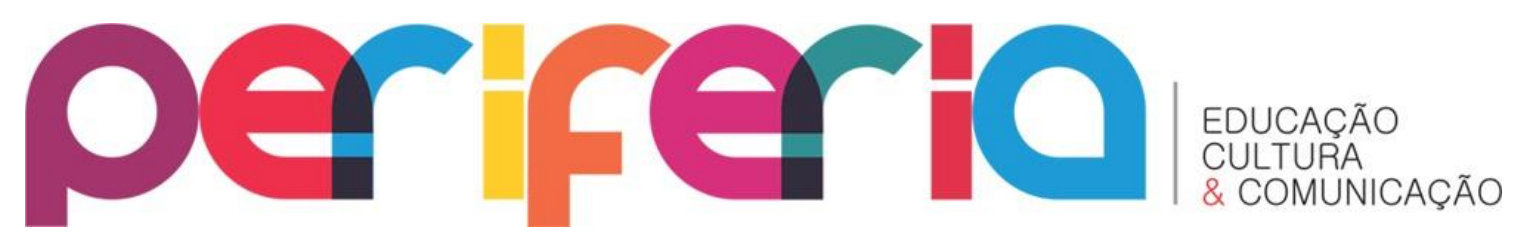

tempo de intensidades, de criação, de vida, de potência, de resgate do que éramos para chegar a ser o que se é (NIETZSCHE, 2008); um reencontro com nossas raízes, com nossa essência.

Quando pensamos nesse resgate ainda na primeira infância, o processo pode ser mais fácil, pois, por mais que já tenham experimentado e que também vivam espíritos de camelo e de leão, mesmo na infância, o espírito de criança ainda pode estar latente.

Foi com essas reflexões que também nos alimentamos a cada encontro com as crianças surdas do INES para buscarmos um diálogo tônico com seus corpos que as convidassem a esse estado de ser criança potente, na perspectiva nietzschiana, como também para nos reconectarmos com essas crianças que vivem em nós, no intuito de também nos alimentarmos dessas experiências e aprendermos, juntos, adultos e crianças, a buscar esse reencontro com nós mesmos.

Diante das reflexões filosóficas já citadas, também entendemos que a ausência do diálogo verbal não as levava a um lugar menor, da falta, da deficiência. Nesse caso, evidenciava-se um diálogo tônico forte, intenso, liberto, que nos tocava, nos afetava e nos transformava. Não buscávamos ensinar nada, mas aprender juntos na interação pulsante de nossos corpos e no desejo de nos potencializarmos cada vez mais com esses encontros.

\section{ESTUDOS SOBRE SURDEZ EM DIÁLOGO COM A EDUCAÇÃO PSICOMOTORA}

Questões sobre a surdez também nos instigava nos estudos e no campo de pesquisa. Nas condições de ouvinte, como dialogar com crianças surdas?

No intuito de estudar sobre a educação de surdos com o foco na filosofia e nas potencialidades do corpo, tornou-se necessário buscar entender quais são os mecanismos sociais, políticos e educacionais que fazem com que a comunidade surda permaneça no lugar de minoridade dentro da sociedade brasileira. 


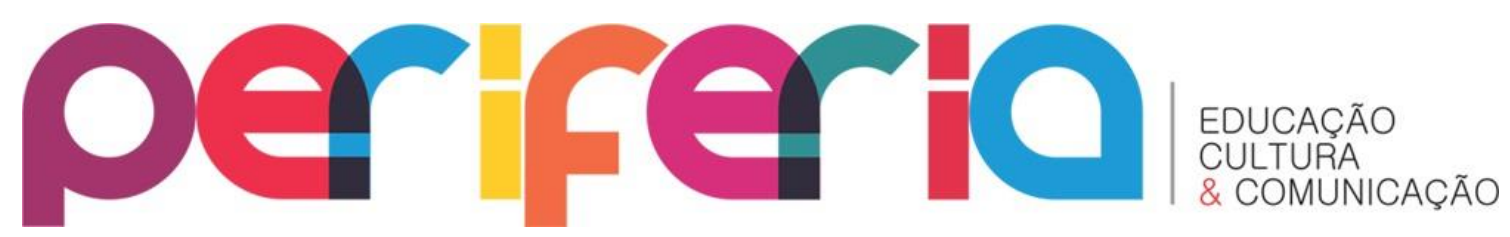

Muito há o que estudar sobre a questão filosófica no que diz respeito ao corpo e à formação de sujeitos e, quando unimos essas reflexões aos estudos sobre a educação de surdos, encontramos respostas, mas também encontramos novos questionamentos.

Através de Foucault (2009), podemos pensar sobre a necessidade de docilização dos corpos, de controle societal e o quanto uma comunidade surda e uma língua de sinais vai contra esse sistema de domesticação e de poder. Como controlar o que não se conhece? Como permitir uma comunicação gestovisual que a própria sociedade majoritária não entende?

Ao final do século XVIII, as manifestações da linguagem gestovisual e das expressões corporais foram proibidas na Europa, em função de uma "onda de puritanismo" nestas sociedades, que passou a manipular os corpos, controlando-os, principalmente através das instituições educacionais, "onde a utilização do tempo e do espaço é pensada com as particularidades do controle e da disciplina física e moral" (LULKIN, 2010, p. 35).

Em evento posterior, a língua de sinais foi erradicada. Aconteceu no Congresso de Milão, em 1880, no qual, dos 174 congressistas, apenas 1 era surdo. Prevaleceu o oralismo como forma de educar a linguagem dos surdos. "Na prática escolar, a primeira medida educativa para coibir o uso da língua de sinais foi obrigar os alunos surdos a sentarem sobre suas mãos" (LULKIN, 2010, p. 38), além dos professores surdos precisarem deixar as escolas. Com essa prática, regulou-se o controle dos corpos dos surdos nas escolas, tanto quanto os dos ouvintes, sendo que, no primeiro caso ainda havia o agravante da dificuldade de estabelecer comunicação verbal através da oralização de surdos.

Cabe trazer estes acontecimentos para esclarecer o quanto a falta de um olhar para a corporeidade interfere negativamente em todo o processo educativo de uma nação, e quanto, no caso dos alunos surdos, essa situação se agrava, pois, enquanto, para os ouvintes, há uma forma eficaz e satisfatória de se comunicar através da verbalização, mesmo com a disciplinarização dos corpos (FOUCAULT, 2009); ao podar os movimentos dos 


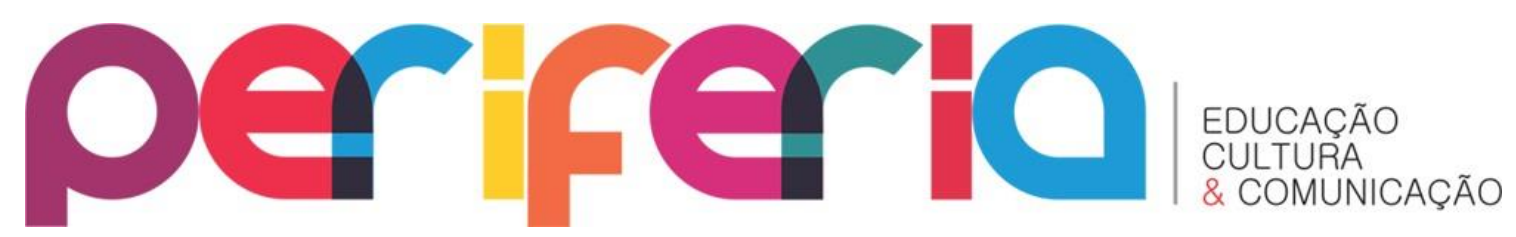

surdos, também se poda o canal mais efetivo de comunicação deles com outros sujeitos e vice-versa.

A comunicação gestovisual existe desde a antiguidade e surgiu como uma forma espontânea das pessoas surdas se comunicarem, mas essa forma de se comunicar sofreu evoluções e involuções. No decorrer dos séculos, criou-se a língua de sinais e esta foi formalizada e espalhada por todos os continentes. Neste período, muitos professores aprenderam a alfabetizar alunos surdos e a desenvolver planos de aula que atendessem suas demandas, facilitando o acesso dos mesmos à sociedade como um todo. Com o passar do tempo, percebida como uma linguagem de contato de poucas pessoas e não compreendida pela maioria da sociedade, a utilização crescente da língua de sinais pela parcela surda da população mundial fez com que os indivíduos ouvintes se sentissem ameaçados por uma linguagem que não dominavam. Este fato, aliado à cultura e prática de controle e disciplina dos corpos, fez com que a classe dominante (composta, em todas as épocas, em sua larga maioria, por sujeitos ouvintes) ganhasse força e poder para castrar as possibilidades de atuação no campo da linguagem dos surdos. Por sua vez, castraram-se, também, maiores possibilidades de aprendizagem cognitiva, o que interferiu imediatamente nas conquistas sociais dos sujeitos surdos.

Goldfeld (2002), ao abordar sobre a educação dos surdos, trouxe a contribuição de Vygotsky ao destacar que a linguagem não é apenas "uma forma de comunicação, mas também [...] uma função reguladora do pensamento" (p. 18). Ela também trouxe a contribuição de Bakhtin ao afirmar que a ideologia é social, enquanto a consciência é individual (p. 50-51). Neste sentido, faz a relação entre o indivíduo surdo e sua relação com a sociedade, destacando que, sem interação, o meio social não se constitui. Sendo assim, sem os movimentos corporais valorizados, como fica a interação dos surdos com o meio social em que vivem? Como esse sujeito se constitui se ele não se identifica, não interage e não se reconhece na sociedade vigente?

Skliar (2010) levantou as questões pertinentes às identidades surdas, reconhecendo-as não como deficiências, como faltas, como fracassos, mas, 


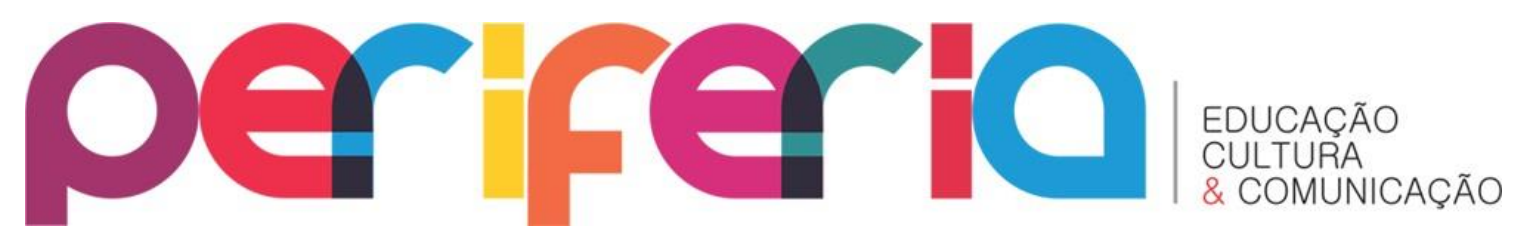

pelo contrário, como uma experiência visual potente, e nós acrescentamos, como uma capacidade de expressão corporal latente. Ao invés dessas identidades serem marcadas pela ausência, elas podem ser percebidas por potencialidades próprias, com construções históricas e sociais significativas.

No contato com sujeitos surdos, é impressionante perceber como, apesar das castrações, das limitações impostas socialmente, há um potencial revelador neles. Mesmo sem escutar e sem poder se comunicar de forma eficaz com a comunidade ouvinte, e mesmo sendo esta última a comunidade dominante da sociedade brasileira, eles formam famílias, trabalham, estudam e aprendem formas de se comunicarem no entorno social. Tal fato revela o que os filósofos já abordavam: há uma potência corporal que não pode ser castrada. Uma potência desconhecida, reveladora e construtora de novos campos de desenvolvimento humano.

Não temos a pretensão de desvelar essa potência, mas buscar, através destes estudos, formas de valorizar as potencialidades desse corpo na educação dos surdos, fazendo uma relação direta com o potencial de cada um, pois eles já revelaram, com seus atos e seus progressos, que seus corpos não paralisam, não despotencializam, diante de amarras impostas pelo sistema político, educacional e social.

\section{O QUE CONCLUIR DESSES DIÁLOGOS TÔNICOS POTENTES COM CRIANÇAS SURDAS?}

A pesquisa revelou muitos caminhos de reflexão e atuação para todos nós. A primeira questão que nos inquietou foi sobre o lugar que ocupávamos. Atualmente, vivemos um olhar desacreditado para a escola, principalmente quando o que se discute é o espaço do brincar, da liberdade de expressão e da potencialização desses corpos. As críticas ocorrem tanto para escolas ditas de ensino regular como para escolas voltadas ao ensino de crianças com deficiências. A lógica cartesiana de separar o corpo da mente para atender a máxima de Descartes (2008), Penso, logo existo!, ainda predomina no 


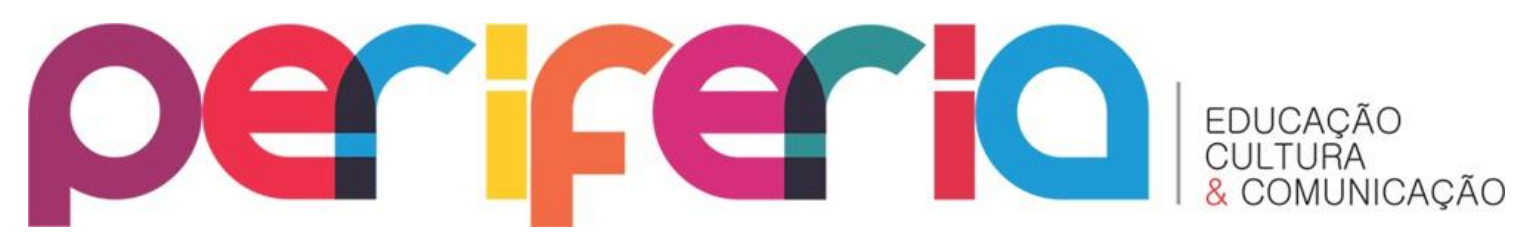

ambiente educacional, por mais que estudos comprovem o quanto a mente faz parte do mesmo corpo que pensa, que relaciona, que se comunica, que sente. O ser humano é único em sua complexidade e indivisibilidade. Não é possível separar a mente do corpo como tantos educadores insistem em suas práticas. Nietzsche, no texto Dos desprezadores do corpo (2011), lançou o desafio a pensar sem o corpo. Para esse filósofo, a mente não é nada mais do que algo do corpo.

Essas reflexões ainda são ampliadas quando questionamos as possibilidades de olhar para a educação de crianças surdas: como elas se comunicam? Como seus corpos são percebidos? Que diálogos tônicos prevalecem? Como empoderá-las diante de uma sociedade que não reconhece o valor dos sujeitos surdos?

Entendemos a dificuldade de adquirirem uma linguagem verbal fluente ainda na primeira infância, mesmo que através de LIBRAS, porque para tal, os adultos com quem ela convive também precisariam ter essa fluência para dialogarem e, assim, na relação, aprenderem a verbalizar (exatamente como acontece com as crianças ouvintes). Na realidade, a maioria dessas crianças é filha de pais ouvintes que, mesmo descobrindo que seus filhos são surdos, ainda na maternidade, e que o primeiro impulso seja aprender LIBRAS, esses pais precisam de tempo para adquirirem a fluência na comunicação gestovisual. Tempo, este, que é caro para quem está chegando no mundo desejoso de comunicação.

A Psicomotricidade traz possibilidades de desenvolver outras formas potentes não só de comunicação, mas também de atuação e apreensão do mundo em que vivem. Através de uma educação psicomotora, é possível perceber o corpo como fio condutor de todo esse processo e as crianças são convidadas a perceberem seus corpos pela saúde e pela sua força. A deficiência é afirmada, mas se torna algo menor diante de tantas possibilidades vitais, potentes e relacionais. É nessa relação, na percepção desses diálogos tônicos, que apostamos como caminho para o desenvolvimento infantil das crianças surdas. 


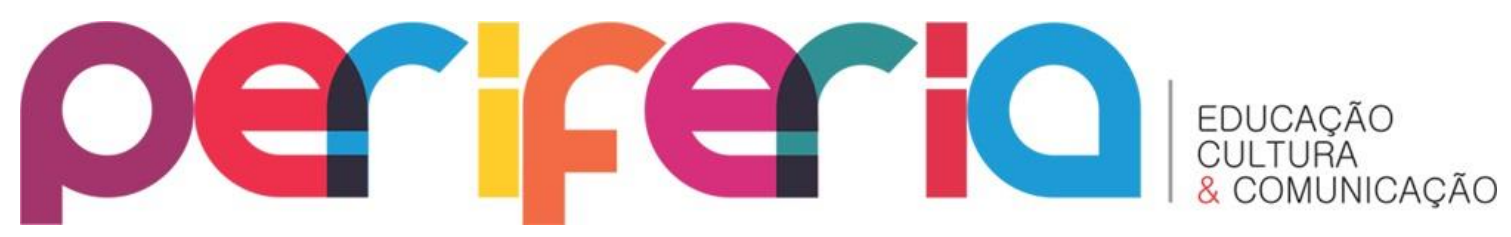

\section{REFERÊNCIAS}

DELGADO, Ana Cristina Coll; MÜLLER, Fernanda. Em busca de metodologias investigativas com as crianças e suas culturas. Cadernos de Pesquisa,. Disponível em: <http://www.scielo.br/pdf/cp/v35n125/a0935125.pdf>, v. 35, n. 125, p. 161-179, maio/ago. 2005.

DESCARTES, René. Discurso dos métodos: Meditações. 2ed. Trad. Roberto Leal Ferreira. São Paulo: Martin Claret, 2008.

FOUCAULT, Michel. Vigiar e punir: história da violência nas prisões. 36ed. Trad. de Raquel Ramalhete. Petrópolis, RJ: Vozes, 2009.

GOLDFELD, Marcia. A criança surda: linguagem e cognição numa perspectiva sociointeracionista. 2ed. São Paulo: Plexus, 2002.

LAPIERRE, Andre; AUCOUTURRIER, Bernard. A simbologia do movimento: Psicomotricidade e educação. 3 ed. Curitiba: Filosofart Editora, 2004.

LULKIN, Sérgio Andrés. 0 discurso moderno na educação dos surdos: práticas de controle do corpo e a expressão cultural amordaçada. In: SKLIAR, Carlos (org.). A surdez: um olhar sobre as diferenças. 4ed. Porto Alegre: Mediação, 2010.

MORIN, Edgar. Os sete saberes necessários à educação do futuro. 9 ed. Trad. Catarina Eleonora F. da Silva e Jeanne Sawaya; revisão técnica de Edgard de Assis Carvalho. São Paulo: Cortez; Brasília, DF: UNESCO, 2004.

NIETZSCHE, Friedrich Wilhelm. Assim falou Zaratustra: um livro para todos e para ninguém. 19ed. Trad. Mário da Silva. Rio de Janeiro: Civilização Brasileira, 2011.

NIETZSCHE, Friedrich Wilhelm. Ecce homo: como alguém se torna o que é. Trad. Paulo César de Souza. São Paulo: Companhia das Letras, 2008.

NIETZSCHE, Friedrich Wilhelm. O nascimento da tragédia. Trad. J. Guinsburg. São Paulo: Companhia das Letras, 2007.

SKLAR, Carlos. Os estudos surdos em educação: problematizando a normalidade. In: SKLIAR, Carlos (org.). A surdez: um olhar sobre as diferenças. 4ed. Porto Alegre: Mediação, 2010. 